\title{
Properties of Cast-In-Place Concrete and Precast Concrete Blocks Incor- porating Waste Glass Powder
}

\author{
Narayanan Neithalath ${ }^{*}, 1$ and Nathan Schwarz ${ }^{2}$
}

\author{
${ }^{1}$ Assistant Professor, Department of Civil and Environmental Engineering, Clarkson University, Potsdam, NY 13699, \\ USA; ${ }^{2}$ Graduate student, Department of Civil and Environmental Engineering, Clarkson University, Potsdam, NY \\ 13699, USA
}

\begin{abstract}
This paper deals with studies on the use of waste glass powder as an effective ingredient in concrete. Studies on cement pastes including mechanical property tests and thermal analysis were used to understand the influence of the glass powder on the cement hydration process and to arrive at an optimal dosage range. Cast-in-place concrete and block mixtures were proportioned with varying dosages of glass powder, and tests for mechanical properties, alkali-silica reaction, and water absorption were carried out. The use of fly ash as a cement replacement material was also adopted in one of the concrete mixtures to compare the performance of glass powder and fly ash in concrete. Though the complete effect of cement dilution was not overcome by the chosen dosage of glass powder, the strength results were comparable to that of control concrete. Moisture intake results of glass powder modified concrete mixtures showed lower total water absorption as well as sorptivity than the control concrete when cured for a longer duration. The expansion due to alkali-silica reaction was also lower for the glass powder modified mixtures. For the concrete block mixtures, it was found that moist curing the blocks after initial steam curing was beneficial in strength improvement. Replacement of $10 \%$ cement with glass powder was found to result in equal or higher compressive strengths of the blocks. In regions where glass powder is locally available, its use as a cement replacement material presents an efficient waste management option, without compromising concrete performance.
\end{abstract}

\section{INTRODUCTION}

The interest of the construction community in using waste or recycled materials in concrete is increasing because of the emphasis placed on sustainable construction, as well as the potential materials-related advantages that some of the waste materials offer. Waste glass is one such material which is receiving renewed attention. In 2005, approximately 12.8 million tons of waste glass was generated in the United States, and only about $20 \%$ of it was recycled [1]. Due to dwindling landfills and increasing cost of land-filling, recycling and reusing glass has become imperative.

Research studies on the use of waste glass in concrete have been reported. Crushed glass aggregates are being used in several decorative concrete applications, and there is reported literature on its use as coarse aggregate in conventional concretes [2-7] and precast blocks [8]. The fact that glass has a high silica content has led to laboratory studies on its feasibility as a raw material in cement manufacture [9, 10]. The use of finely divided glass powder as a cement replacement material has yielded positive results [11-16]. Glass is amorphous with a high silica content, thus making it potentially pozzolanic when the particle size is less than 75 $\mu \mathrm{m}$ [12]. Studies have also shown that finely ground glass does not contribute to alkali-silica reaction $[5,11]$. The environmental and economic benefits of reusing waste glass in concrete have been outlined in [17].

\footnotetext{
*Address correspondence to this author at the Assistant Professor, Department of Civil and Environmental Engineering, Clarkson University, Potsdam, NY 13699, USA; Tel: 315-268-1261; Fax: 315-268-7985;

E-mail: nneithal@clarkson.edu
}

In the research reported in this study, waste / by-product glass powder from an industrial and highway safety glass bead manufacturing process is used as a cement replacement material in cast-in-place concrete and precast concrete block manufacturing. Optimal dosage range of this glass powder is chosen based on cement paste studies. Selected properties of the glass powder modified mixtures are compared with the properties of concretes containing the same amount of fly ash. The ultimate aim of this work is to ascertain the performance of concretes containing glass powder, and compare it with the performance of fly ash modified concretes. This is expected to provide: (i) a sustainable waste management option to producers of waste glass powder, and (ii) necessary data to concrete and block manufacturers on the applicability of glass powder in concrete. Successful implementation of waste glass powder in concrete will provide a boost to the use of such non-conventional materials which are typically of local or regional origin.

\section{STUDIES ON CEMENT PASTES FOR MATERIAL CHARACTERIZATION AND OPTIMAL DOSAGE SELECTION}

Before using a cement replacement material in concrete, it is important to understand its influence on cement hydration and associated properties. In this study, to understand the relative effectiveness of fine and coarse glass powder in cementitious systems, studies were conducted on cement pastes made with a water-cementing materials ratio $(\mathrm{w} / \mathrm{cm})$ of 0.42. A detailed treatment on the influence of glass powder on the behavior of cement pastes is presented here in order to lay the foundation for the experiments on cast-inplace concrete and concrete blocks. 


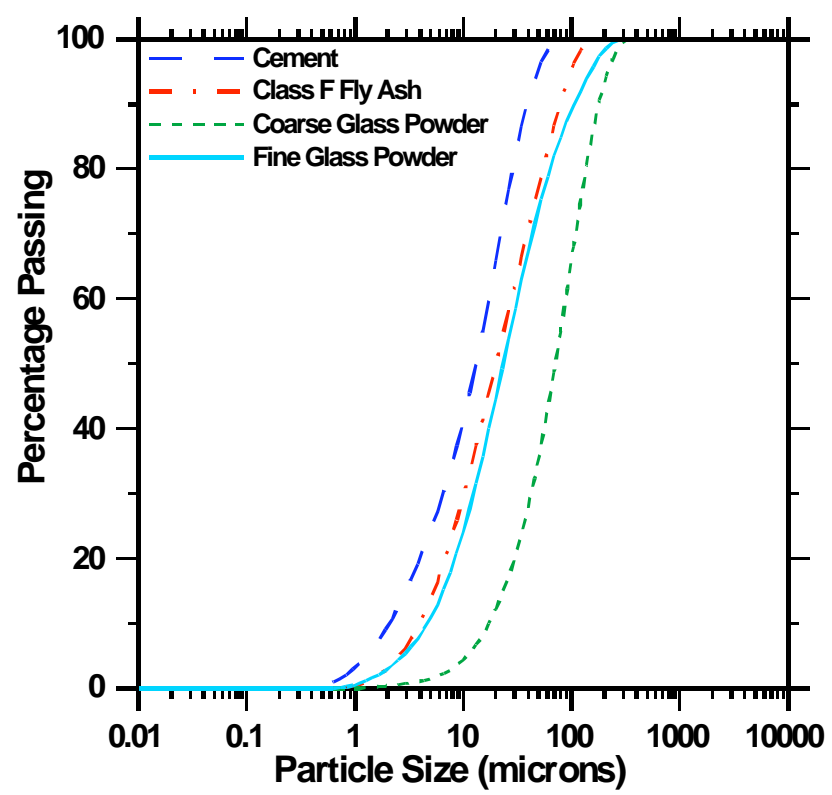

Fig. (1). Particle size distribution of cement, fly ash, and the glass powders used in this study.

\subsection{Material Characteristics and Test Methods}

Type I/II ordinary Portland cement conforming to ASTM C 150 was used for this study. The coarse glass powder had a particle size such that $60 \%$ is finer than $88 \mu \mathrm{m}$, and the fine glass powder had about $75 \%$ of the particles finer than 45 $\mu \mathrm{m}$. In order to compare the effects of glass power to a commonly used supplementary cementing material, a Class F fly ash was also used. The particle size distribution of fly ash was very similar to that of fine glass powder. Fig. (1) shows the particle size distributions of cement, glass powders and fly ash used in this study, obtained using a laser particle size analyzer. The chemical composition of these materials can be found in Table 1. The glass powder has a higher silica content than the cement and fly ash, while having the least alumina content. The calcium oxide content of the glass powder is higher than that of fly ash. The sodium oxide content of the glass powder is very high, as is expected of soda glass. Detailed studies by the authors on hydration characteristics of cement and durability of concretes containing glass powder has shown that the high $\mathrm{Na}_{2} \mathrm{O}$ content in glass powder does not adversely influence concrete performance $[18,19]$.

The compressive strengths of cement pastes were determined in accordance with ASTM C 109 after they were cured for specified durations in saturated limewater. Nonevaporable water contents using the loss on ignition method

Table 1. Chemical Composition of Cement, Glass Powder, and fly Ash Used in this Study

\begin{tabular}{|c|c|c|c|}
\hline Composition $(\%$ by Mass) & Cement & Glass Powder & Fly Ash (Class F) \\
\hline \hline Silica $\left(\mathrm{SiO}_{2}\right)$ & 20.2 & 72.5 & 50.24 \\
\hline Alumina $\left(\mathrm{Al}_{2} \mathrm{O}_{3}\right)$ & 4.7 & 0.4 & 28.78 \\
\hline Iron oxide $\left(\mathrm{Fe}_{2} \mathrm{O}_{3}\right)$ & 3.0 & 0.2 & 5.72 \\
\hline Calcium oxide $(\mathrm{CaO})$ & 61.9 & 9.7 & 5.86 \\
\hline Magnesium oxide $(\mathrm{MgO})$ & 2.6 & 3.3 & 1.74 \\
\hline Sodium oxide $\left(\mathrm{Na}_{2} \mathrm{O}\right)$ & 0.19 & 13.7 & $0.96^{*}$ \\
\hline Potassium oxide $\left(\mathrm{K}_{2} \mathrm{O}\right)$ & 0.82 & 0.1 & -- \\
\hline Sulfur trioxide $\left(\mathrm{SO}_{3}\right)$ & 3.9 & 0.36 & 0.51 \\
\hline Loss on ignition & 1.9 & 72 & 2.8 \\
\hline Fineness, $\%$ passing $45 \mu \mathrm{m}$ & 95 & 2490 & 74 \\
\hline Density $\left(\mathrm{kg} / \mathrm{m}^{3}\right)$ & 3150 & & 2250 \\
\hline
\end{tabular}

${ }^{*}$ Equivalent alkalis 
at various ages were used to estimate the degrees of hydration of the pastes. Small pieces from the samples (approximately 1-2 $\mathrm{mm}$ in size) cured in saturated limewater were pulverized and soaked in acetone to stop further hydration. The pulverized samples were heated in an oven at $105^{\circ} \mathrm{C}$ for 24 hours, followed by heating in a muffle furnace at $1050^{\circ} \mathrm{C}$ for 3 hours. The non-evaporable water content $\left(w_{n}\right)$ was obtained as the difference in mass between the sample heated at $105^{\circ} \mathrm{C}$ and $1050^{\circ} \mathrm{C}$ normalized by the mass after heating to $1050^{\circ} \mathrm{C}$, and correcting for the loss on ignition of unhydrated cement (or of the unhydrated cement and the glass powder multiplied by their respective mass fractions). The heat evolution in the specimens due to the hydration of the cementing materials was calculated using NT BUILD 480 [20] where as the heat lost to the surroundings from the semi-adiabatic chamber was calculated using the well known conductive heat loss equation. The calcium hydroxide content in the pastes, which is a useful indicator of the secondary reaction of the cement replacement materials, was determined using thermogravimetric analysis.

\subsection{Compressive Strength of Cement Pastes}

Fig. (2) depicts the compressive strengths of coarse glass powder, fine glass powder, and fly ash modified cement pastes cured under saturated conditions for 28 days. From Fig. (2a), it can be noticed that, at 28 days, the coarse glass powder modified pastes reach only about $80 \%$ and $70 \%$ of the compressive strength of plain paste for $10 \%$ and $20 \%$ cement replacement by glass powder respectively. This is not withstanding the increased degrees of hydration of the available cement in the presence of glass powder [16]. The

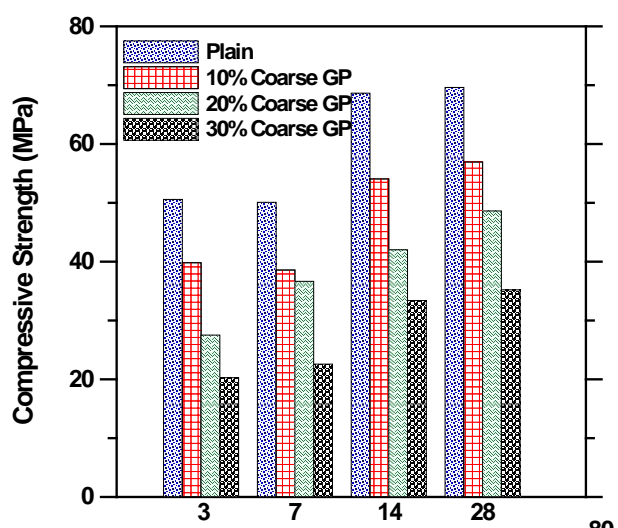

(a)

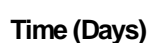

percentage reductions in compressive strengths are more than the replacement levels of cement in coarse glass powder modified cement pastes. Thus the use of coarse glass powder as a cement replacement material cannot be justified. However, this could prove to be an ideal material as a filler in high performance and self-consolidating concretes, as detailed in [21].

Fig. (2b) shows that, at 28 days, fine glass powder modified pastes show compressive strengths very close to that of the plain paste, even at $20 \%$ replacement levels. The compressive strengths of fly ash modified pastes at the same replacement levels as that of fine glass powder are shown in Fig. (2c). The fine glass powder modified pastes show slightly higher strengths than the corresponding fly ash modified pastes until 28 days. However, later age tests show that the fly ash modified pastes gain strength at a much faster rate due to the pozzolanic reaction while the secondary reaction of glass powder is not very efficient [16]. This could be related to the particle sizes of glass powder. It has been stated that glass powder with a particle size such that $75 \%$ passing $45 \mu \mathrm{m}$ is marginal as a pozzolan, where as it requires glass to be finer than $23 \mu \mathrm{m}$ to be a very effective pozzolan [12]. The higher compressive strengths of glass powder modified pastes until 28 days as compared to that of fly ash pastes can be attributed to the enhancement in cement hydration.

Based on the results of the compressive strength results discussed above, only the fine glass powder is used for further studies.
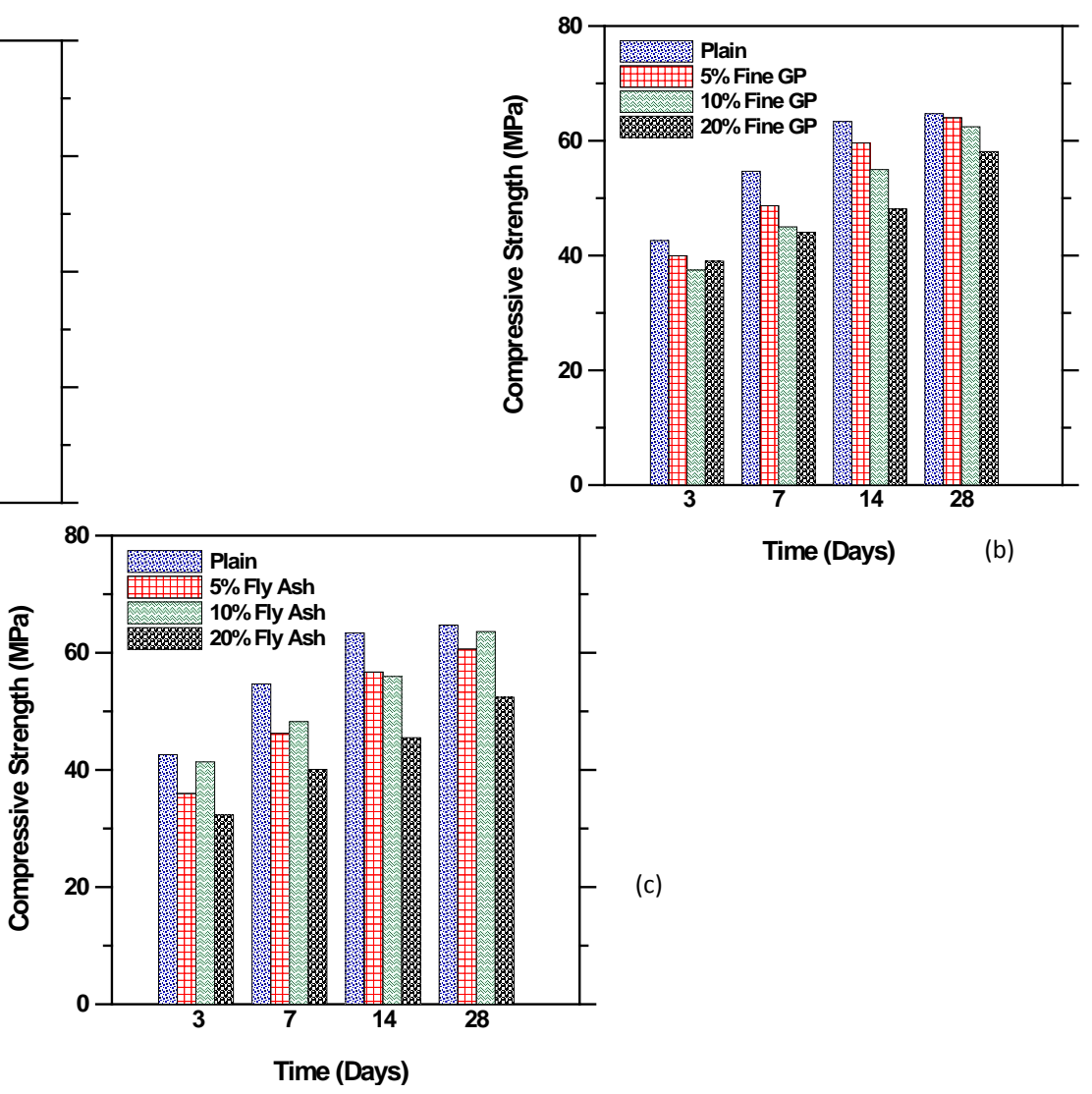

Time (Days)

(b)

Fig. (2). Compressive strength development of cement pastes containing: (a) coarse glass powder, (b) fine glass powder, and (c) Class F fly ash. 


\subsection{Degrees of Hydration and Heats of Hydration of Glass Powder and fly Ash Modified Pastes}

The degrees of hydration of cement pastes are generally calculated by dividing the non-evaporable water contents determined from loss-on-ignition tests by the non-evaporable water content of a completely hydrated paste (which can be theoretically calculated from the Bogue composition and the non-evaporable water contents of the compound phases). When coarse glass powder (or any other coarse material, e.g., limestone powder) is used as a filler, the degree of hydration determined using the above mentioned method can be corrected using the mass fraction of the cement in the mixtures (since these coarse materials do not react). However, when cement replacement materials with secondary reaction of their own are used, determination of the total degree of hydration becomes complicated because of the difficulty in separating the bound water contents due to the cement hydration and secondary reaction. Hence the authors have provided a model based on mixing equation for the overall degree of hydration of cement pastes $\left(\alpha_{T}\right)$ containing a cement replacement material having its own secondary reaction.

$\alpha_{T}=\frac{\left(w_{n}\right)_{T}}{\left(w_{n}\right)_{c-\infty}}+\left(w_{n}\right)_{r} m_{r}\left[\frac{1}{\left(w_{n}\right)_{r-\infty}}-\frac{1}{\left(w_{n}\right)_{c-\infty}}\right]$

$\left(w_{n}\right)_{T}$ is the total non-evaporable water content of the paste, $\left(w_{n}\right)_{r}$ is the non-evaporable content attributable to the replacement material, $\left(\mathrm{w}_{\mathrm{n}}\right)_{\mathrm{c}-\infty}$ and $\left(\mathrm{w}_{\mathrm{n}}\right)_{\mathrm{r}-\infty}$ are the ultimate nonevaporable water contents of the cement and the replacement material respectively, and $\mathrm{m}_{\mathrm{r}}$ is the mass fraction of the replacement material. The model formulation could be found in [16].

Iso-response curves for the predicted degrees of hydration using this model are shown in Fig. (3) for pastes modified with glass powder. For a given age, the degree of hydra-

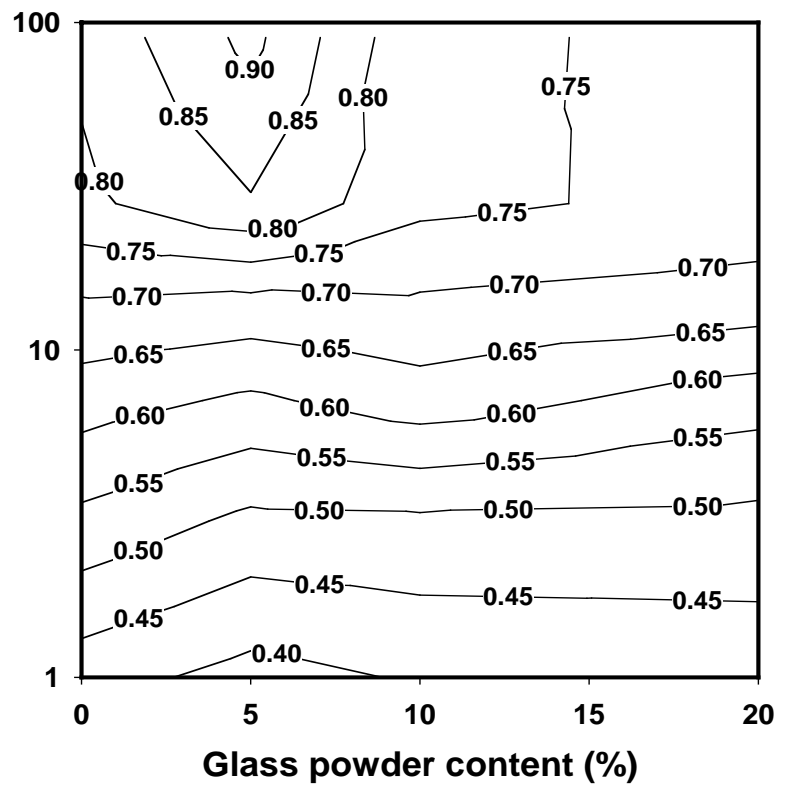

Fig. (3). Isoresponse curves for degrees of hydration of pastes modified with glass powder.

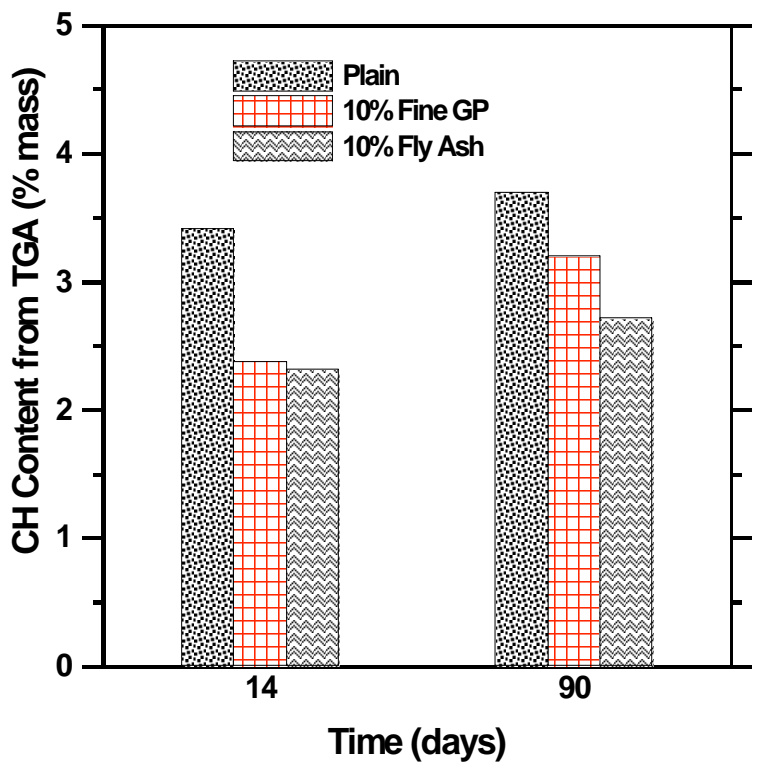

Fig. (4). Calcium hydroxide contents of plain and modified pastes after 90 days.

tion for pastes modified with $5-10 \%$ glass powder is seen to be higher than that of the plain paste. This indicates that, for the w/cm chosen, $5-10 \%$ glass powder is beneficial in the paste system.

Fig. (4) shows the calcium hydroxide $(\mathrm{CH})$ loss, represented as the percentage mass lost between 440 and $520^{\circ} \mathrm{C}$ when the pastes were subjected to thermogravimetric analysis after 14 and 90 days of curing. At both early and later ages, the $\mathrm{CH}$ loss is higher for the plain paste than any of the modified pastes, as expected. At 14 days, there is no appreciable difference in the $\mathrm{CH}$ contents between pastes modified with $10 \%$ glass powder or $10 \%$ fly ash. At 90 days, the fly ash modified pastes are observed to have lower $\mathrm{CH}$ contents than the glass powder modified pastes, but the glass powder modified paste has a lower $\mathrm{CH}$ content than the plain paste.

The heats of hydration of pastes with $0,5 \%, 10 \%$, and $20 \%$ of cement replaced by fine glass powder are shown in

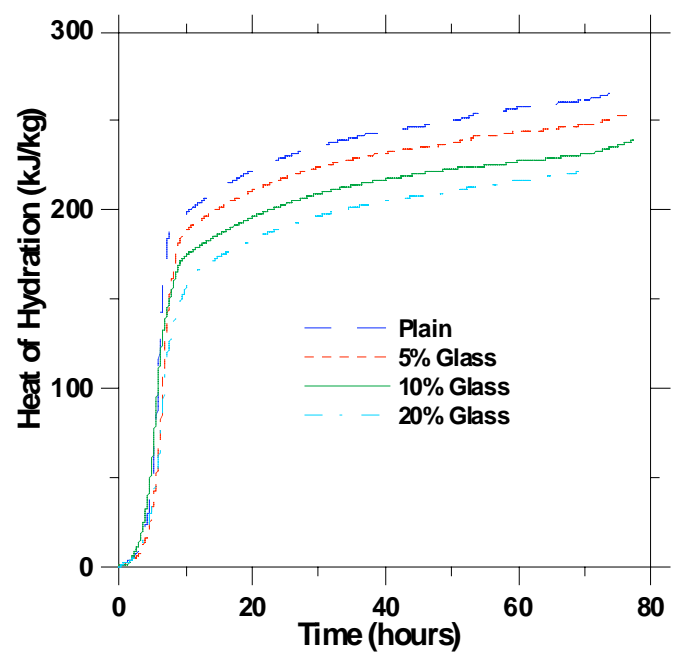

Fig. (5). Heats of hydration of plain and glass powder modified cement pastes. 
Fig. (5). Heats of hydration as a function of time were calculated from the semi-adiabatic time-temperature data. It is seen from Fig. (5) that increasing replacement levels of glass powder result in reduced cumulative heat of hydration as compared to the plain paste.

The aforementioned studies on degrees of hydration and $\mathrm{CH}$ contents of glass powder modified pastes, and their comparison with fly ash modified pastes show that a replacement of $5 \%$ or $10 \%$ of cement by the fine glass powder is feasible in cementitious systems. The heats of hydration studies show that these replacement levels result in glass powder modified pastes developing lesser heat than the conventional pastes. This is also a beneficial attribute for mass concretes because of the reduced risks of thermal cracking.

\section{EXPERIMENTAL PROGRAM FOR THE STUDY ON CAST-IN-PLACE CONCRETES AND CONCRETE BLOCKS}

\subsection{Mixture Proportions}

For the plain and fine glass powder modified concretes used in this study, the same materials as described in section 2.1 were used. Twelve concrete mixtures with w/cm ranging between 0.35 and 0.45 , and containing various dosages of glass powder or fly ash were proportioned. However, discussions in this paper are limited to four concrete mixtures having a w/cm of 0.40 . Two of the mixtures had $5 \%$, and $10 \%$ of cement replaced by fine glass powder (designated as 5GP and $10 \mathrm{GP}$ respectively), one mixture had $10 \%$ of cement replaced by fly ash (designated as 10FA) for comparison, and the other was a control mixture. A certain mass of cement was directly replaced by glass powder or fly ash in these mixtures without any adjustment in the contents of other ingredients in the mixture. However, a previous study has reported results where the w/cm of glass powder and fly ash modified mixtures was adjusted to produce similar workability as the control concrete [18]. Needless to say, such an approach will present the replacement materials in a better light, but the aim of this study is to show that the use of glass powder as a direct cement replacement without any other changes in the concrete mixture is feasible.

The concrete mixtures were made in accordance with ASTM C 192, and cylindrical and prismatic specimens cast for various tests. The fresh concrete properties including air content (ASTM C 231) and slump (ASTM C 143) were also determined. The specimens were cured at $23^{\circ} \mathrm{C}$ and $98 \% \mathrm{RH}$ until testing. Table $\mathbf{2}$ shows the mixture proportions and fresh concrete characteristics.

The concrete blocks were produced in a block plant that manufactures concrete masonry products. Type III cement as per ASTM C 150 was used for the precast blocks. The w/cm used in the regular blocks was 0.32 . For glass powder modified mixtures, slightly higher and lower w/cm also was used to understand its influence on block properties. Two sizes of blocks - $41 \mathrm{~mm}$ x $194 \mathrm{~mm}$ x $397 \mathrm{~mm}$, and $92 \mathrm{~mm}$ x $194 \mathrm{~mm}$ x $397 \mathrm{~mm}$ - were produced. In addition to w/cm of 0.32 , a slightly higher w/cm of 0.33 was used in $41 \mathrm{~mm} \mathrm{x} 194 \mathrm{~mm}$ x $397 \mathrm{~mm}$ blocks, and slightly lower w/cm of 0.31 and 0.30 for $92 \mathrm{~mm}$ x $194 \mathrm{~mm}$ x $397 \mathrm{~mm}$ blocks. The molds containing the fresh concrete were compacted under pressure and vibration. The blocks pressed out of the molds were transferred into a steam curing chamber where they were cured for about 18 hours. After the steam curing duration, the blocks for testing were transferred to a moist curing chamber where they were kept until the respective testing ages.

\subsection{Test Methods}

The compressive strengths of $100 \mathrm{~mm}$ diameter x 200 $\mathrm{mm}$ long concrete cylinders were determined in accordance with ASTM C 39. The percentage of permeable voids in the specimen was determined in accordance with ASTM C 642. The total mass of water absorbed when subjected to surface ponding (1D absorption), and the sorptivity of the concretes were determined after 14 and 90 days of curing. For this test, $50 \mathrm{~mm}$ thick slices were cut from $100 \mathrm{~mm}$ diameter x 200 $\mathrm{mm}$ long cylinders after the corresponding curing duration. These slices were dried in an oven at $70^{\circ} \mathrm{C}$ for atleast 48 hours and then cooled to room temperature in a dessicator. The sides and bottom of the specimen were covered with a water resistant tape, with a dyke created around the open face to retain water. Water was added to the exposed face and allowed to seep into the concrete. The mass of the specimens were measured at frequent intervals up to 28 days from the start of the ponding test. The amount of water taken in by the specimens was divided by the area exposed to water to obtain the normalized water intake. This test method, when continued for a long period of time, say 28 days, has been used along with a combined sorption-diffusion equation

Table 2. Mixture Proportions (for $1 \mathrm{~m}^{3}$ of Concrete) and Fresh Properties of Concrete

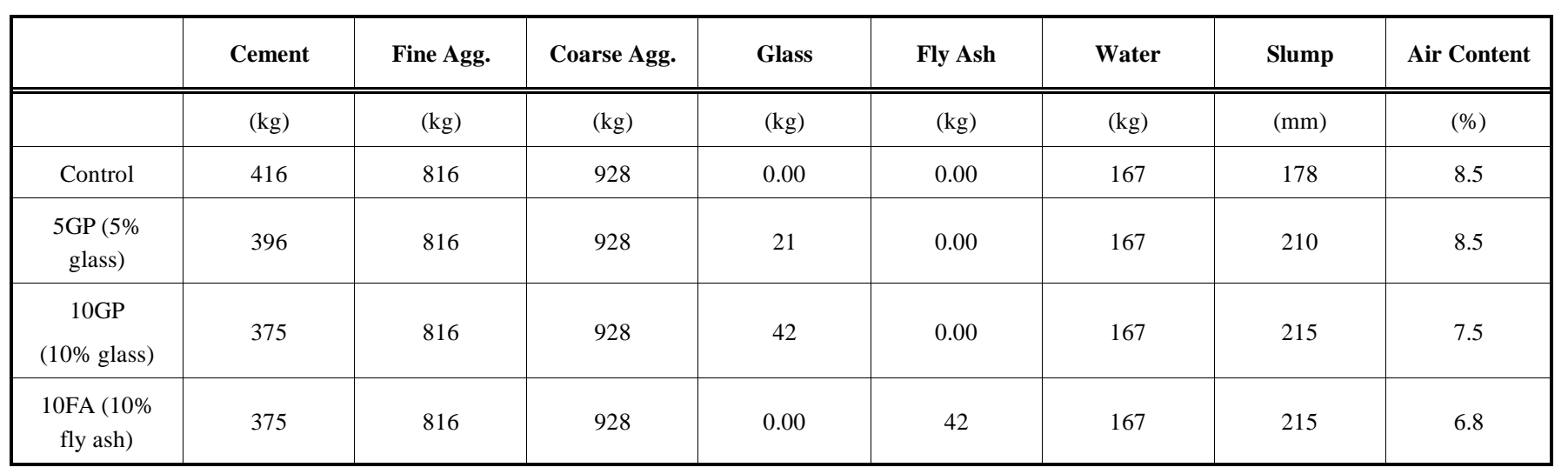


to extract the moisture transport parameters including long term sorptivity and moisture diffusion coefficient of a variety of plain and modified concrete mixtures [18, 22, 23].

The alkali-silica reactivity (ASR) of glass powders were investigated using the ASTM C 1260 test method on mortar bars. The concrete blocks were cut into cubes of $41 \mathrm{~mm}$ or $92 \mathrm{~mm}$ sides depending on their minimum dimensions, and the compressive strengths determined as per ASTM C 109. The flexural strengths of concrete blocks were determined on prismatic specimens $250 \mathrm{~mm}$ long and either $42 \mathrm{~mm}$ or 92 $\mathrm{mm}$ cross section cut from the blocks. The water absorption of block mixtures after 24 hour immersion in water was determined using ASTM C 642. Cubes of sizes similar to that used for compressive strength tests were used for water absorption. The specimens were dried at $105 \pm 5^{\circ} \mathrm{C}$ in an oven for 24 hours, and weighed $\left(\mathrm{m}_{\mathrm{D}}\right)$. They were then immersed in water for a further 24 hours and weighed again $\left(\mathrm{m}_{\mathrm{W}}\right)$. The water absorption (w) is calculated as:

$w=\frac{m_{W}-m_{D}}{m_{D}} \times 100 \%$

\section{RESULTS, ANALYSIS AND DISCUSSION}

\subsection{Studies on Cast-in-place Concrete}

\subsubsection{Compressive Strength}

Fig. (6) shows the compressive strength development of the concrete mixtures. Cement was replaced by either $5 \%$ or $10 \%$ of glass powder or $10 \%$ of fly ash by mass. The control concrete shows a higher strength than the modified mixtures at all ages. The 5\% glass powder modified mixture (5GP) shows strengths equal to that of 10FA mixture at earlier ages, and the lowest strength at later ages. The influence of secondary hydration of fly ash is seen in the strength of the 10FA mixture at later ages. However $10 \%$ replacement of cement by fly ash is not enough to compensate for the cement dilution as seen from the later age compressive strength. The 10GP mixture shows higher strength than the

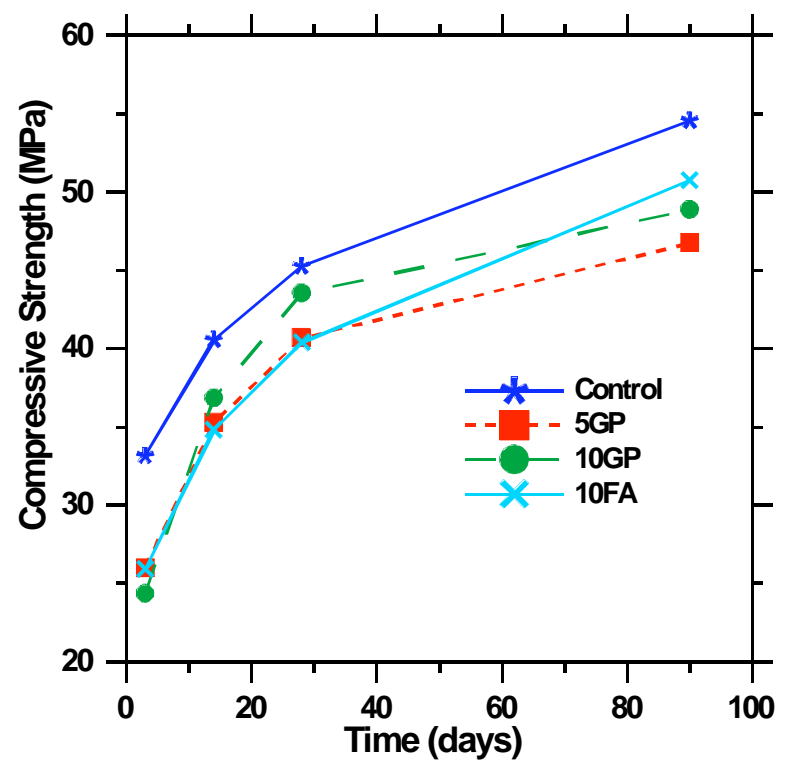

Fig. (6). Compressive strength development of concrete mixtures.
5GP mixture. The 10GP mixture shows compressive strengths closer to that of the control concrete (the difference is less than 5\%), and higher than 10FA mixtures at 14 and 28 days. The enhancement in cement hydration facilitated by the lower water absorption of glass powder, and the secondary reaction of glass powder (albeit weaker than that of fly ash) is responsible for this behavior. Even though the strength loss due to dilution effect is not completely compensated by the use of glass powder, a $10 \%$ replacement of cement by glass powder seems to be a viable option in concretes that are designed for 28 day compressive strengths.

\subsubsection{Percentage of Permeable Voids}

The percentage of permeable voids in the control and modified concretes are shown in Fig. (7). This test was carried out after curing the specimens for either 14 or 90 days in a moist environment. In this test method, pores in the concrete specimen are filled by immersion in water followed by boiling the water containing the specimen. Except for the 5GP mixture, Fig. (7) shows that the concretes show lower absorption when cured for longer duration, as expected. There is no noticeable difference in the percentage of permeable voids between the control, 10GP, and 10FA mixtures. The pore space that is not emptied during the drying procedure used, or not filled with water when immersed and boiled is not accounted for in the absorption. Hence these values should not be used as indicators of the total porosity of the samples or to ascertain the densification of the pore structure caused by secondary reaction. However, the absorption values facilitate a comparison between the control and modified mixtures. The $1 \mathrm{D}$ moisture intake method described in the following section provides a better understanding of the change in material microstructure when cement replacement materials are used.

\subsubsection{One-Dimensional Moisture Intake and Sorptivity}

Fig. (8) depicts the total mass of water absorbed by the concrete specimens normalized by the exposed area, after 28

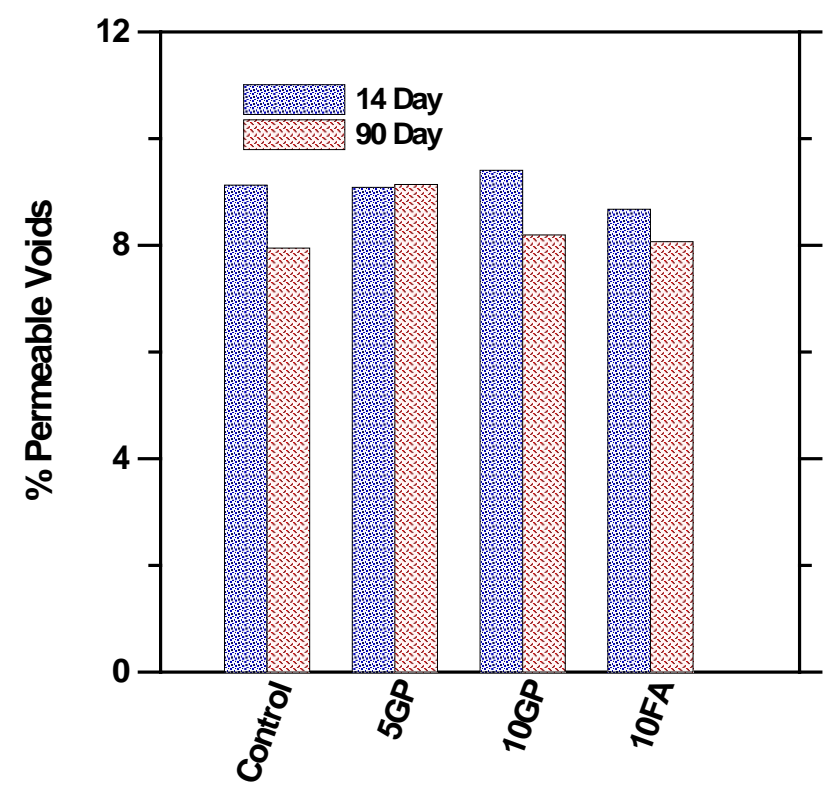

Fig. (7). Permeable voids in the plain and modified concrete mixtures cured for 14 and 90 days. 


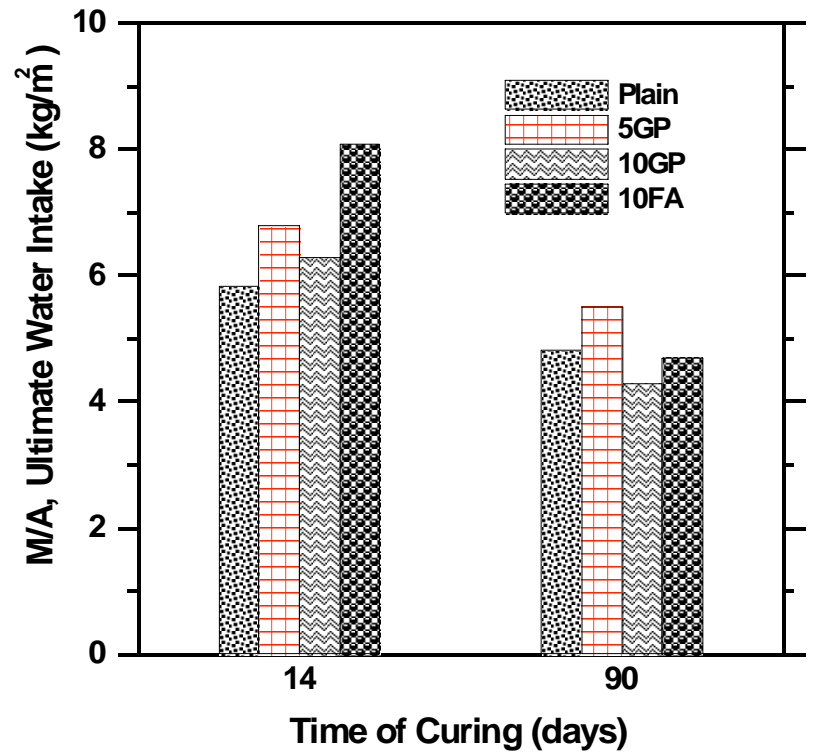

Fig. (8). Ultimate water intake of plain and modified concrete mixtures.

days of ponding test. When subjected to ponding after 14 days of curing, the control concrete absorbs the lowest mass of water, because of the presence of larger amount of cement, and thus more hydration products. For all the modified mixtures, the normalized water intake is higher, with the 10FA mixture showing the highest amount of water intake. This is not surprising because the secondary reaction of fly ash might not have started at this age, leading to an increased pore volume in such mixtures. When this result is compared with the absorption value of 10FA mixture from (Fig. 7) (where the 10FA mixture did not seem to absorb more water as compared to the control specimen), it is obvious that maintaining a constant surface concentration that drives water into the specimen through predominantly capillary sorption at early times, and diffusion at later times gives a more accurate picture of the water intake capacity of the concretes than the immersion and boiling method. More importantly, this approach can lead to quantifiable inferences about the microstructure of the material.

After 90 days of curing, a reversal in the above trend can be observed from (Fig. 8). The 10FA mixture has a normalized water intake similar to or lower than that of the control concrete, indicating the secondary reaction of fly ash at later ages. The 10GP mixture shows the lowest normalized water intake among all the specimens studied. The enhancement in cement hydration, combined with the secondary reaction of glass powder is believed to be responsible for this observation. From the viewpoint of moisture intake also, it is seen that a $10 \%$ replacement of cement with glass powder is a feasible option.

Fig. (9) shows the sorptivities of the control and modified concretes cured for 14 days and 90 days. Sorptivity is the dominant mechanism of moisture ingress into concretes at short periods of exposure (a few hours), especially near partially saturated or unsaturated surfaces, and is defined as the absorption of water by capillary pores and transport by capillary action. Sorptivity is determined in this paper from the

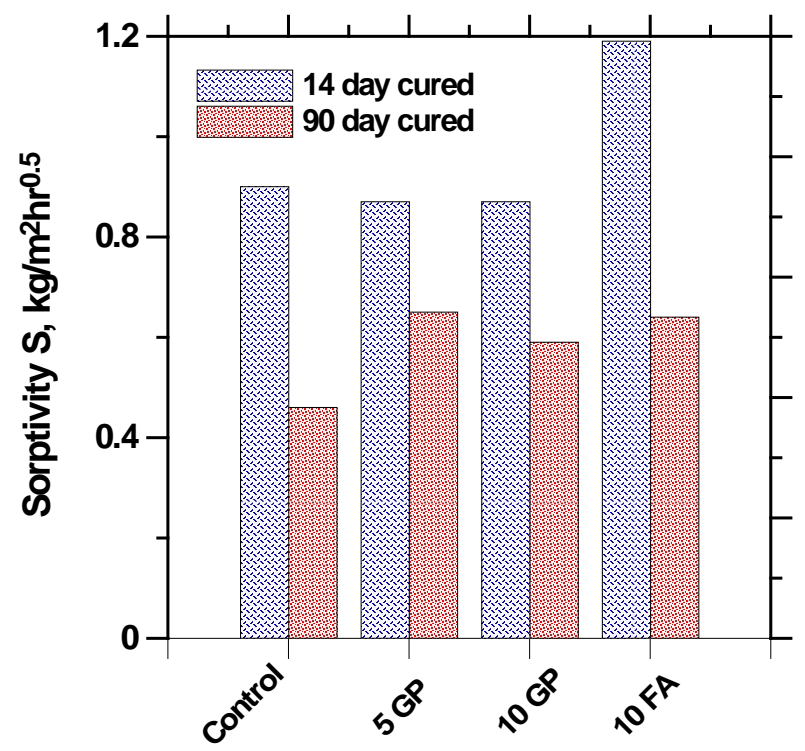

Fig. (9). Sorptivity of plain and modified concrete mixture.

slope of the normalized water intake vs. time plot for the first four hours. It can be seen from (Fig. 9) that, when the curing duration is increased, the sorptivity decreases. The sorptivity values follow a similar trend to that of the total water intake. The sorptivities of the 10GP and 10FA mixtures are very similar after 90 days of curing, indicating that the glass powder modified concretes perform similarly to fly ash modified concretes in this aspect.

\subsubsection{ASR Expansion}

The expansions of mortar bars containing 5\%,10\%, or $20 \%$ glass powder or fly ash by mass as replacement for cement were determined according to the procedure described in ASTM C 1260. A reactive siliceous sand was used as the aggregate. It has been reported that this test method can be used to ascertain the influence of glass powder on the expansion of mortars containing supplementary cementing materials $[11,24]$.

The expansion of mortar bars after 14 days of exposure to $1 \mathrm{~N} \mathrm{NaOH}$ and $80^{\circ} \mathrm{C}$ is shown in Fig. (10). The replacement of cement by either glass powder or fly ash results in reduction in expansion of mortar bars as compared to the control mixture. The reduction in expansion is also proportional to the dosage of the cement replacement material. As can be readily observed from (Fig. 10), fly ash is much more efficient in controlling expansion than the glass powder. The effectiveness of low-calcium, low-alkali fly ashes in reducing the expansion due to ASR is well known. Within the dosages considered in this study, incorporation of glass powder in the mixture is not able to reduce the expansion to less than $0.10 \%$. However, replacement of $20 \%$ of cement by fly ash results in an expansion far lower than $0.10 \%$. A finer and thus more reactive glass powder can be expected to further reduce the expansion. However, the effects of release of a higher amount of sodium need to be explored in such a case. 


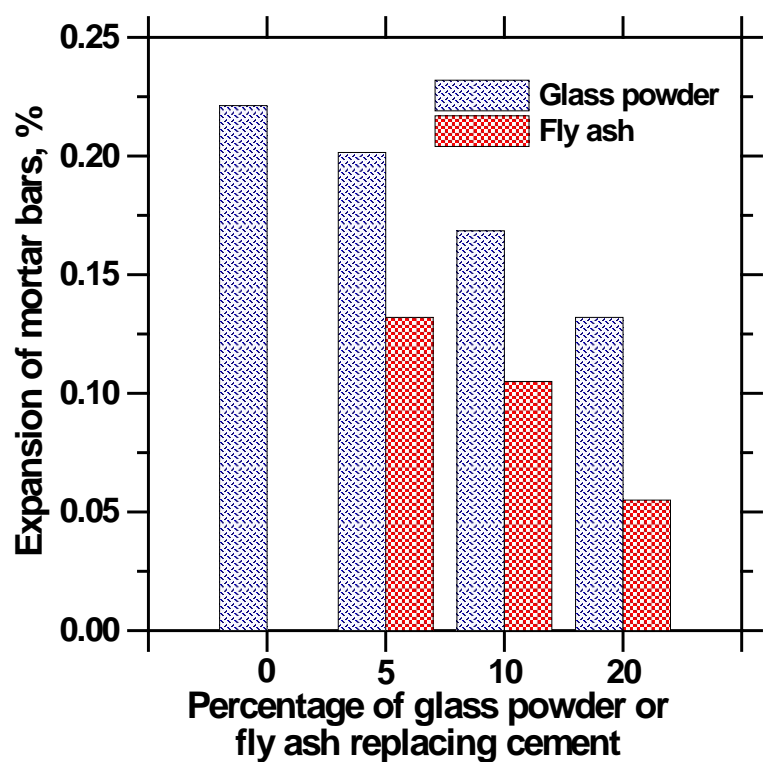

Fig. (10). ASR expansion of plain and modified mortar mixture.

\subsection{Studies on Precast Concrete Blocks}

The results of experimental studies on the properties of precast concrete blocks incorporating glass powder are detailed in this section. The concrete blocks made in the block manufacturing plant were transported to the laboratory on the day after casting. They were then moist cured for a further 13 days in a curing chamber.

\subsubsection{Compressive Strength}

The compressive strength tests were conducted on cubes of sides $42 \mathrm{~mm}$ or $94 \mathrm{~mm}$ (depending on the shortest dimension of the block) cut from the blocks. Fig. (11a) shows the compressive strength variation of the $42 \mathrm{~mm}$ cubes made from $42 \mathrm{~mm} \times 194 \mathrm{~mm} \times 397 \mathrm{~mm}$ size blocks, while (Fig. 11b) shows the strength of $92 \mathrm{~mm}$ cubes cut from $92 \mathrm{~mm} x$

(a)

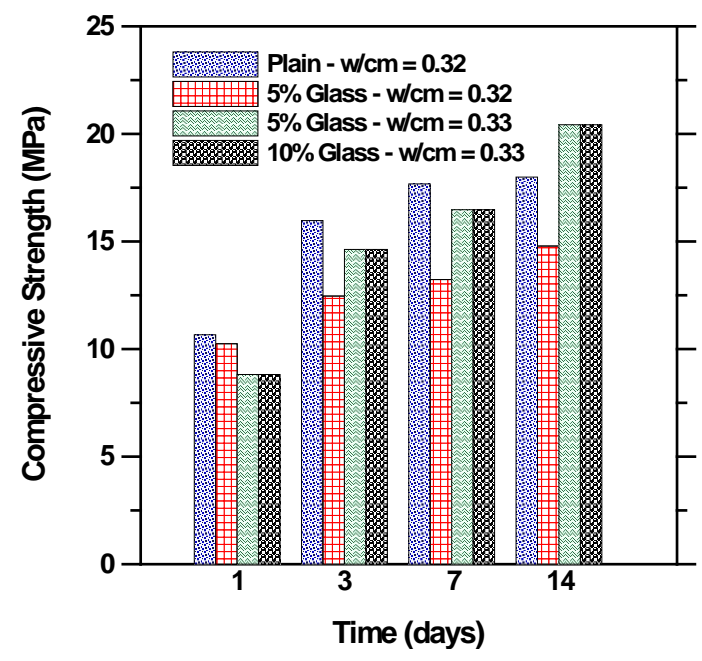

$194 \mathrm{~mm}$ x $397 \mathrm{~mm}$ size blocks. Replacement of cement by glass powder at $5 \%$ and $10 \%$ by mass at similar or slightly higher w/cm compared to that of the plain mixture is dealt with in Fig. (11a) where as (Fig. (11b) shows the results for only $10 \%$ replacement of cement and slightly lower w/cm than the plain mixture. The compressive strengths of the cubes of either size at the same age are almost the same, and no size effect is observed. It can be noticed that moist curing after one day of steam curing is capable of further enhancing the compressive strength of concrete blocks. A close to $100 \%$ strength enhancement is observed in some cases when moist cured for 14 days after a day of steam curing.

From (Fig. 11a), it can be observed that at early ages (until 7 days), the strength of the glass powder modified mixtures are lower than that of the control mixture, irrespective of the glass powder content. The $5 \%$ glass powder modified mixture at the same $w / \mathrm{cm}$ as that of the plain mixture is seen to have the lowest strength, especially after the first day. The dilution effect of the glass powder might not be compensated by increased cement hydration and the hydration of the glass powder at this dosage and w/cm. At 14 days, the $10 \%$ glass powder mixtures with a slightly higher w/cm show slightly higher compressive strengths than the control mixture. Better dispersion of the cement and glass powder and an increased degree of hydration might be the reason for this observation. The increase in compressive strength might have also be facilitated by the better compaction achieved at a slightly higher water content. The fact that the $10 \%$ glass powder modified block mixtures have equal or higher compressive strengths than the plain block mixture at similar or slightly higher w/cm shows the feasibility of using a certain amount of glass powder as cement replacement in concrete blocks.

Fig. (11b) shows the compressive strength development in $92 \mathrm{~mm}$ x $194 \mathrm{~mm}$ x $397 \mathrm{~mm}$ blocks with 10\% replacement of cement by glass powder. The important observation from this figure is that, at later ages, the compressive strengths decrease for both plain and glass powder modified mixtures of reduced w/cm. Immediately after steam curing (1 day), the strength reduction in low w/cm mixtures with respect to the (b)

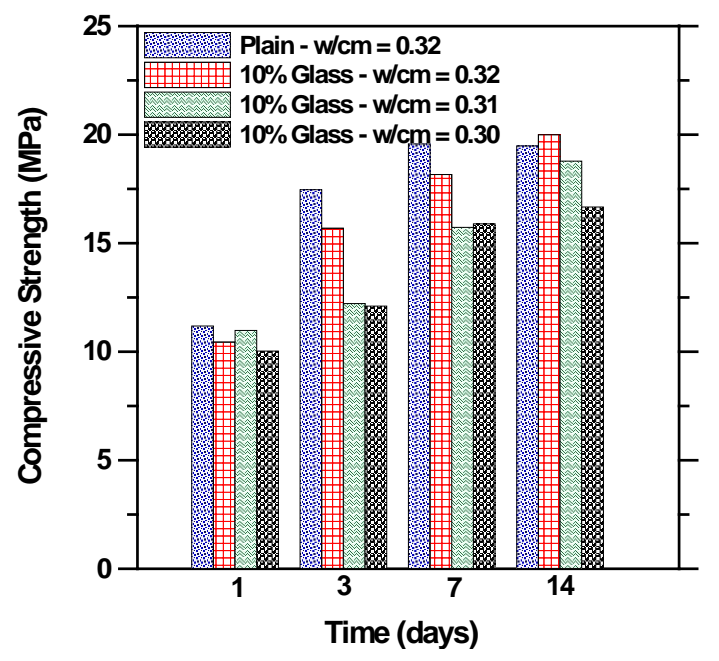

Fig. (11). Compressive strength development of concrete block mixtures: (a) higher w/cm than control, and (b) lower w/cm than control. 


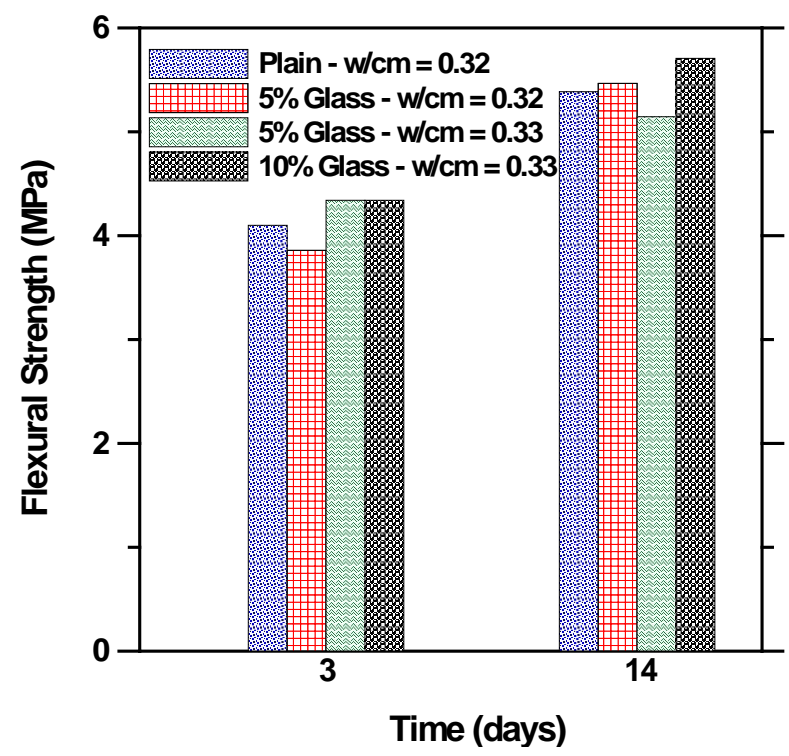

Fig. (12). Flexural strength of concrete block mixtures.

plain mixture is not very evident but further moist curing brings this out because the cement grains that are not hydrated early on are being hydrated in the presence of moisture.

\subsubsection{Flexural Strength}

The flexural strengths were determined on prismatic specimens cut from $42 \mathrm{~mm}$ x $194 \mathrm{~mm}$ x $397 \mathrm{~mm}$ size blocks. Fig. (12) shows the flexural strength of the plain and glass powder modified block mixtures after 3 and 14 days of moist curing following one day of steam curing. It is seen that the flexural strength also increases with moist curing duration. There is no statistically significant difference in flexural strengths between the plain and the glass powder modified mixtures at the same $\mathrm{w} / \mathrm{cm}$ or slightly increased $\mathrm{w} / \mathrm{cm}$. The results of flexural strength test once again prove that the replacement of $10 \%$ of cement by glass powder will not detrimentally affect the mechanical properties of the concrete block.

\subsubsection{Water Absorption}

Table 3. Water Absorption for Concrete Block Mixtures
Table 3 lists the water absorption for the block mixtures of varying glass powder contents and w/cm investigated in this study. The water absorption of mixtures with a slightly higher w/cm is lower than that of the plain mixture as seen from this Table. The mixture with $10 \%$ glass powder content and a w/cm of 0.33 has a lower water absorption compared to the plain mixture with a w/cm of 0.32 . These observations are in line with the compressive strength results of these mixtures. The higher amount of hydration products formed because of the presence of glass powder, and a slightly higher w/cm that helps better compaction are the reasons for this also, as was with the compressive strength results. Even between the $5 \%$ glass replacement levels at w/cm of 0.32 and 0.33 , it can be seen that the higher $w / \mathrm{cm}$ mixture has lower water absorption. Lowering the $\mathrm{w} / \mathrm{cm}$ results in generally increasing water absorption values within the range investigated in this study, as can be seen from (Table 3 ). The mixture with $10 \%$ glass powder at the same w/cm as the plain mixture has a lower water absorption.

\section{SUMMARY AND CONCLUSIONS}

The main objective of this paper was to provide results of studies conducted on waste glass powder modified cast-inplace concrete and concrete blocks in order to ascertain the influence of glass powder on the properties of these construction materials. Tests on compressive strength, degrees of hydration, and heat of hydration of modified cement pastes were conducted to characterize the material and select optimal dosages. It has been shown in this paper that the performance of fine glass powder in cement pastes can be compared to that of pastes modified with fly ash, until a certain cement replacement level.

A few concrete mixtures were proportioned using either fine glass powder or fly ash as cement replacement material. A $10 \%$ cement replacement by glass powder was found to be optimal as far as compressive strength was concerned, with the difference in strength between the plain concrete and modified concretes being less than $5 \%$. The complete effect of dilution was not overcome by increased hydration of cement and secondary hydration of glass powder at this dosage. Flexural strength results also showed similar trends. One dimensional moisture intake data is seen to provide better insights into the moisture transport phenomenon than the

\begin{tabular}{|c|c|c|c|c|}
\hline Block Size & Specimen Size (mm) & Mixture Description & w/cm & Water Absorption (\%) \\
\hline \multirow{3}{*}{$41 \mathrm{~mm}$ x $194 \mathrm{~mm}$ x $397 \mathrm{~mm}$} & \multirow{3}{*}{$41 \mathrm{~mm}$ cubes } & Plain & 0.32 & 6.55 \\
\hline & & $5 \%$ glass powder & 0.33 & 6.12 \\
\hline & & $10 \%$ glass powder & 0.33 & 5.82 \\
\hline \multirow{3}{*}{$92 \mathrm{~mm}$ x $194 \mathrm{~mm}$ x $397 \mathrm{~mm}$} & \multirow{3}{*}{$92 \mathrm{~mm}$ cubes } & $10 \%$ glass powder & 0.32 & 6.81 \\
\hline & & $10 \%$ glass powder & 0.31 & 7.43 \\
\hline & & $10 \%$ glass powder & 0.30 & 7.59 \\
\hline
\end{tabular}


absorption after immersion and boiling method. While the control concrete showed the lowest moisture intake when subjected to $1 \mathrm{D}$ moisture intake test after 14 days of moist curing, the $10 \%$ glass powder modified concrete showed the lowest intake when specimens were cured for 90 days. This is because of the enhancement in cement hydration, combined with the secondary reaction of glass powder. The sorptivities of the concretes also followed a similar trend. The glass powder showed potential to reduce the expansion due to alkali-silica reaction, but in this respect, fly ash at similar dosages was found to perform better.

Compressive strength tests on concrete blocks made by replacing $5 \%$ or $10 \%$ cement by glass powder showed that moist curing after the initial steam curing duration increases the strength of the blocks. Glass powder modified block mixtures showed slightly lower strength than the control mixture at very early ages, but this trend was reversed at 14 days. The block mixtures with $10 \%$ glass powder replacing cement showed equal or higher compressive strengths than the plain block mixture at similar or slightly higher $w / \mathrm{cm}$. Flexural strength results also point to the feasibility of using $10 \%$ glass powder as cement replacement in precast concrete blocks.

In summary, the applicability of a waste glass powder as a partial cement replacement material in cast-in place concrete as well as concrete blocks from the viewpoint of mechanical and durability issues has been demonstrated in this paper. Comparison to fly ash also has been brought out where applicable. The results from this study are expected to provide an impetus to the use of waste glass powder as a partial cement replacement material in regions where this material is locally available. The economical and environmental impacts result from the potential to use waste glass powder in concrete, and the possibility of reducing cement content in concrete.

\section{REFERENCES}

[1] Environmental Protection Agency (EPA), "Municipal Solid Waste Generation, Recycling, and Disposal in the United States: Facts and Figures for 2005," EPA-530-F06-039, October 2006.

[2] C.D. Johnston, "Waste glass as coarse aggregate for concrete", Journal of Testing and Evaluation, vol. 2, pp. 344-350, September 1974.

[3] S.B. Park, B.C. Lee, and J.H. Kim, "Studies on mechanical properties of concrete containing waste glass aggregate", Cement and Concrete Research, vol. 34, pp. 2181-2189, 2004.

[4] I.B. Topcu and C. Canbaz, "Properties of concrete containing waste glass", Cement and Concrete Research, vol. 34, pp. 267-274, 2004.

[5] W. Jin, C. Meyer, and S. Baxter, "Glascrete - Concrete with glass aggregates", ACI Materials Journal, vol. 97, pp. 208-213, 2000.

[6] C. Meyer, N. Egosi, and C. Andela, "Concrete with waste glass as aggregate", in Proceedings of Recycling and reuse of glass cullet,
Concrete technology unit of ASCE and University of Dundee, 2001.

[7] C. M. Sangha, A. M. Alani, and P. J. Walden, "Relative strength of green glass cullet concrete", Magazine of Concrete Research, vol. 56, pp. 293-297, June 2004.

[8] C. S. Lam, C. S. Poon, and D. Chan, "Enhancing the performance of pre-cast concrete blocks by incorporating waste glass - ASR consideration", Cement and Concrete Composites, vol. 29, pp. 616625, 2007.

[9] G. Chen, H. Lee, K. L .Young, P. L .Yue, A. Wong, T. Tao, and K. K. Choi, "Glass recycling in cement production - an innovative approach", Waste Management, vol. 22, pp. 747-753, 2002.

[10] Z. Xie, and Y. Xi, "Use of recycled glass as a raw material in the manufacture of Portland cement", Materials and Structures, vol. 35, pp. 510-15, April 2002.

[11] A. Shayan, and A. Xu, "Value-added utilization of waste glass in concrete", Cement and Concrete Research, vol. 34, pp. 81-89, January 2004.

[12] Y. Shao, T. Lefort, S. Moras, and D. Rodriguez, "Studies on concrete containing ground waste glass". Cement and Concrete Research, vol. 30, pp. 91-100, January 2000.

[13] A. Shayan, and A. Xu, "Performance of glass powder as a pozzolanic material in concrete: A field trial on concrete slabs". Cement and Concrete Research, vol. 36, pp. 457-468, March 2006.

[14] C. Shi, Y. Wu, C. Riefler, and H. Wang, "Characteristics and pozzolanic reactivity of glass powders". Cement and Concrete Research, vol. 35, pp. 987-993, May 2005.

[15] T. D. Dyer, and R. K. Dhir, "Chemical reactions of glass cullet used as cement component", Journal of Materials in Civil Engineering, vol. 13, pp. 412-417, December 2001.

[16] N. Schwarz, and N. Neithalath, "Influence of a fine glass powder on cement hydration: Comparison to fly ash and modeling the degree of hydration", Cement and Concrete Research, vol. 38, pp. 429-436, April 2008

[17] C. Shi, and K. Zheng, "A review on the use of waste glasses in the production of cement and concrete", Resources, Conservation and Recycling, vol. 52, pp. 234-247, 2007.

[18] N. Schwarz, H. T. Cam, and N. Neithalath, "Influence of a fine glass powder on the durability characteristics of concrete and its comparison to fly ash", Cement and Concrete Composites, vol. 30, pp. 486-496, 2008.

[19] N. Schwarz. and N. Neithalath, "Quantifying the cementing efficiency of fine glass powder and its comparison to fly ash", in Proceedings of the $1^{\text {st }}$ International Conference on Recent Advances in Concrete Technology, Washington D.C., 2007, p.12.

[20] NT BUILD 480, Nordtest method: Heat of hydration. FIN-02150 Espoo, Finland, 1997.

[21] N. Schwarz, M. DuBois, and N. Neithalath, "Electrical conductivity based characterization of plain and coarse glass powder modified cement pastes", Cement and Concrete Composites, vol. 29, pp. 656-666, October 2007.

[22] N. Neithalath, "Analysis of moisture diffusion in mortars and concrete using a sorption-diffusion approach", ACI Materials Journal, vol. 103, pp. 209-217, 2006.

[23] N. Neithalath, "Evaluating the short-term and long-term moisture transport phenomena in lightweight aggregate concretes", Magazine of Concrete Research, vol. 59, pp. 435-445, 2007.

[24] M. D. A. Thomas, and F. A. Innis, "Use of the accelerated mortar bar test for evaluating the efficacy of mineral admixtures for controlling expansion due to alkali-silica reaction", Cement, Concrete, and Aggregates, vol. 21, pp.157-164, December 1999.

(C) Neithalath and Schwarz; Licensee Bentham Open.

This is an open access article licensed under the terms of the Creative Commons Attribution Non-Commercial License (http://creativecommons.org/licenses/by-nc/3.0/) which permits unrestricted, non-commercial use, distribution and reproduction in any medium, provided the work is properly cited. 